\title{
SEMINARIO-TALLER SOBRE NORMAS DE VANCOUVER Y GESTORES BIBLIOGRÁFICOS
}

\section{Vancouver protocol and reference management software seminar and workshop *Carlos Amílcar Fuentes Romero}

\section{INTRODUCCION}

Las normas de Vancouver son un conjunto de reglas para la presentación de artículos que se pretenden publicar en revistas médicas. Fue el resultado de una reunión de los principales editores, que se celebró en Vancouver, Canadá, en 1978. La intención de este grupo fue establecer directrices sobre el formato que deben poseer los trabajos enviados para su publicación en revistas médicas. Los gestores bibliográficos son herramientas que recogen las referencias bibliográficas de las bases de datos de investigación (catálogos de bibliotecas, índices, bases de datos de revistas científicas, etc.), y le permiten organizar las citas y la bibliografía para sus proyectos. En este artículo, se presenta el resumen del contenido desarrollado en el Seminario-Taller sobre normas de Vancouver y Gestores bibliográficos desarrollado los días 6 y 7 de octubre del 2014, en la Universidad Nacional Autónoma de Honduras Valle de Sula (UNAH-VS).

\section{SEMINARIO TALLER}

El pasado mes de octubre se impartió el Seminario-Taller sobre Normas de Vancouver y Gestores Bibliográficos, dirigido a los miembros del Concejo Editorial de la Revista Científica de la Escuela Universitaria de las Ciencias de la Salud (EUCS) y Acta Pediátrica del Post-grado de pediatría de la UNAH-VS. (Figura No.1, 2)

*Profesor Escuela Universitaria de Ciencias de la Salud. Universidad Nacional Autónoma de Honduras, EUCS, UNAH-VS. Médico Salubrista Dirigir correspondencia a: carlos.fuentes@unah.edu.hn,

cafr5993@yahoo.com

Recibido: 16 de Noviembre 2,014 Aprobado 20 de Febrero 2,015
Figuras $\mathbf{N}^{\circ}$ 1, 2: Seminario Taller sobre Normas de Vancouver y Gestores Bibliográficos
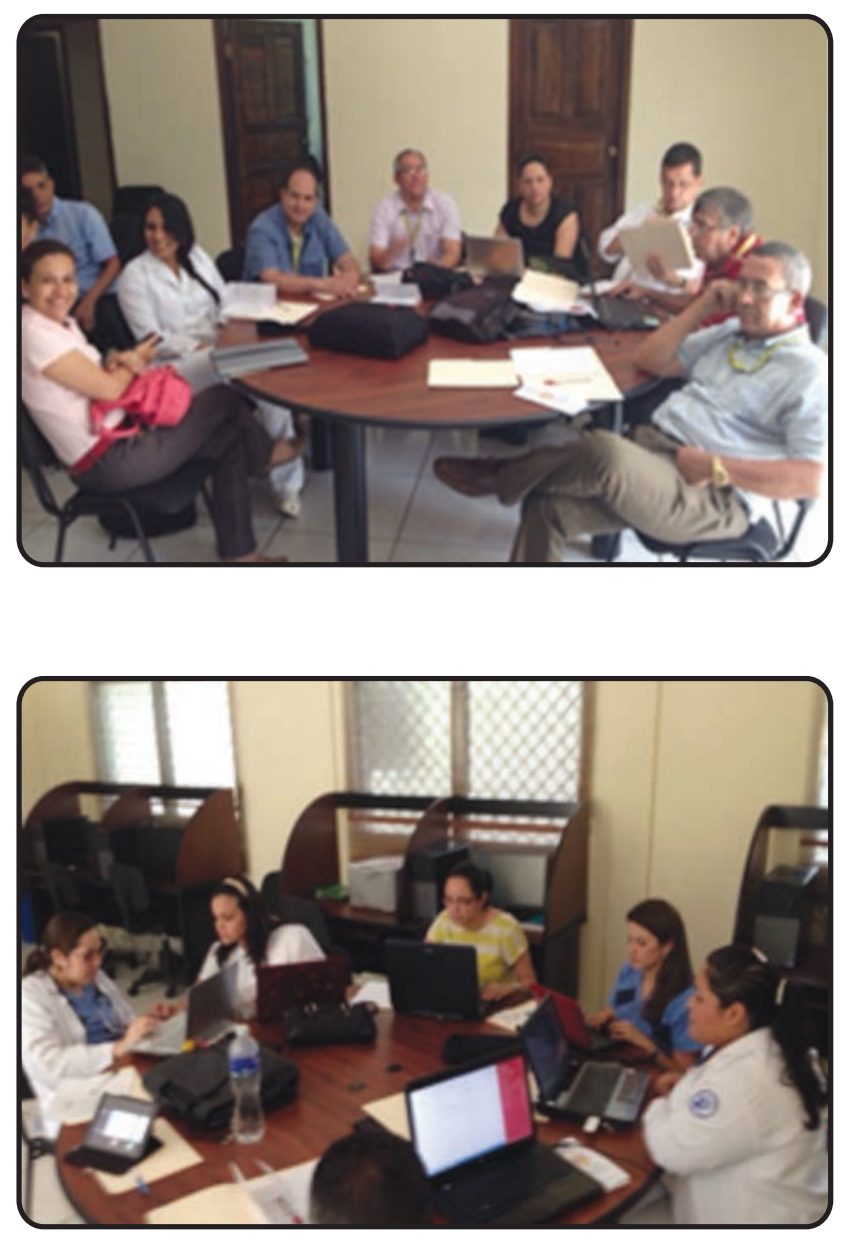

Miembros de los Concejos Editoriales de la Revista Científica EUCS y de Acta Pediátrica Hondureña.

Facilitado por la Dra. Martha Cecilia García, (Figura No. 3) Directora de la Biblioteca Médica Nacional, con el propósito de que los miembros de estos concejos mejoren en la revisión de los trabajos que reciben para corrección y posterior publicación, así como actualización con nuevas herramientas usadas como apoyo al proceso de investigación. 
Figura N³: Inauguración del Seminario-taller sobre normas de Vancouver y Gestores bibliográficos

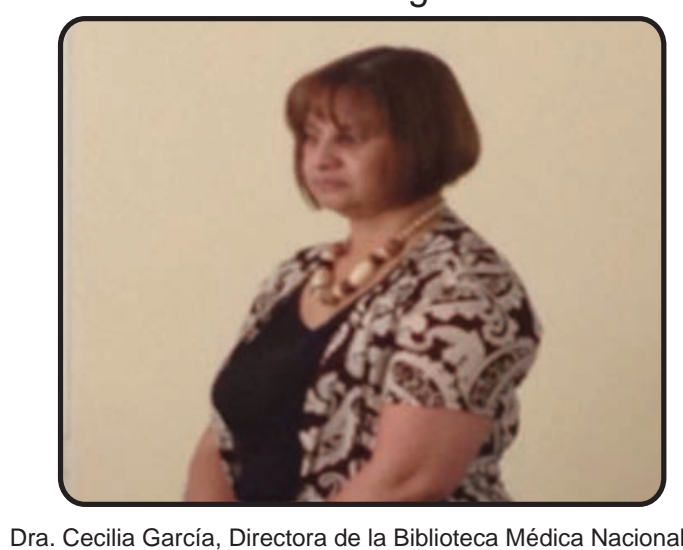

Dichas directrices fueron publicadas por primera vez en 1979, con el título de Requisitos de Uniformidad para la presentación de manuscritos enviados a revistas biomédicas (Uniform Requirements for Manuscripts Submitted to Biomedical Journals). En estos se incluyeron formatos para referencias bibliográficas dados por la Biblioteca Nacional de Medicina de los Estados Unidos de América (National Library of Medicine NLM of the United States).

Este grupo llegó a ser conocido como el Grupo Vancouver; creció y evolucionó hasta convertirse en el Comité Internacional de Editores de Revistas Médicas (International Committee of Medical Journal Editors ICMJE). Se reúnen anualmente y se dedican a revisar las directrices y su renovación. La vigente es la actualización de las mismas hasta el mes de diciembre del 2014, versión publicada en inglés. A la fecha cambiaron su nombre a Recomendaciones para la conducta, reporte, edición y publicación de manuscritos en Revistas Médicas (Recommendations for the Conduct, Reporting, Editing and Publication of Scholarly Work in Medical Journals) ICMJE desarrolló estas recomendaciones para revisar las mejores prácticas y estándares éticos en la realización y presentación de informes de investigación y otros materiales publicados en revistas médicas, y para ayudar a los autores, editores y otros involucrados en la revisión por pares y publicación biomédica.

Las recomendaciones también pueden proporcionar información útil sobre la edición médica y proceso de publicación de los medios de comunicación, los pacientes y sus familias, y los lectores en general. ${ }^{(1,2)}$

Los gestores bibliográficos son herramientas que recogen las referencias bibliográficas de las bases de datos de investigación (catálogos de bibliotecas, índices, bases de datos de revistas científicas, etc.), y le permiten organizar las citas y la bibliografía para sus proyectos. Además le ayudan en la citación de sus trabajos de investigación permitiendo la creación automática de citas, bibliografía y notas al pie de página. ${ }^{(3)}$

Las razones para utilizar este sistema de gestión de citas incluye: organización, prevención de errores de transcripción o tipográficos, facilitar la cita y la creación de las bibliografías. Existen varios gestores bibliográficos, entre estos: EndNoteWeb, Zotero, Mendeley y Citavi. Tienen la misma finalidad: organizar las citas bibliográficas para los proyectos encaminados a la publicación científica. ${ }^{(3)}$

Mencionaremos en especial a Citavi, este es un programa para el manejo de referencias para Microsoft Windows, publicado por la Academia Suiza para Software, con sede en 
la ciudad de Wadenswil, en la república suiza. Desciende de un programa para referencias llamado LiteRat desarrollado en la Universidad Heinrich Heine, en 1995. Ha evolucionado desde la versión 1.0 en 1995, hasta la 4.0, la usada actualmente, disponible para usarse en idiomas inglés, francés, alemán, italiano, polaco, portugués y español. ${ }^{(4)}$

La presentación de CITAVI para el usuario es para el manejo de las referencias, organización y planificación del conocimiento. En línea el usuario puede acceder a bases de datos y catálogos. Los archivos de las bases de datos pueden ser guardados en un programa de Windows. El gestor CITAVI, al usarse en línea, ayuda a incluir cartas, videos, manuales bajados de la red e información ofrecida en foros y/o conferencias. Las referencias adquiridas con este gestor bibliográfico incluyen: las adquiridas en fuentes comunes, archivos locales (PDF), bases de datos, importación de referencias de otros programas y formatos (EndNoteWeb,ProCite,etc), de buscadores en internet (Google Chrome, Yahoo, Mozilla, etc), textos e imágenes de expertos, libros de texto con International Standard Book Number (ISBN), páginas web transformadas a documento PDF, trabajos con varios procesadores de palabras, publicaciones en todos los estilos comunes de citas, etc. ${ }^{(4)}$

CITAVI es el gestor bibliográfico promovido en la Universidad Nacional Autónoma de Honduras (UNAH), en vista de un acuerdo suscrito con Swiss Academy Software, empresa creadora del CITAVI, en la que establece que la UNAH tiene la responsabilidad de promocionar el gestor bibliográfico en Honduras y Centroamérica.(5)

\section{CONCLUSIONES}

1. Al explicar estos conceptos, nos damos cuenta que el seminario-taller sobre normas de Vancouver y gestores bibliográficos, desarrollado fortalecerá la actividad desarrollada por concejos editoriales de la Revista Científica de la EUCS y de Acta Pediátrica, del Postgrado de Pediatría de la UNAH-VS en lo que a revisión de los trabajos enviados para su publicación y la organización de la información se refiere, además permitirá que evolucionemos en esta labor acorde con la era tecnológica que actualmente vivimos, facilitando la asesoría que se le brinde a los autores de los trabajos recibidos.

2. Las publicaciones nacionales estén acordes a las normas internacionales de publicación, lo que posibilita su inserción en bases de datos de prestigio a nivel regional y mundial.

3. Mejorar el posicionamiento y visibilidad de los autores nacionales y de la institución en los rankings internacionales de investigación. Este es un avance en la planificación y organización del conocimiento, cuyo fin se centra en ofrecer así un servicio cada día mejor de alta calidad a nuestros usuarios.

\section{AGRADECIMIENTO}

A la Dra. Martha Cecilia García, Directora de la Biblioteca Medica Nacional, por impartir el seminario-taller y revisar este artículo de opinión. 


\section{BIBLIOGRAFÍA}

1. Universidad de Málaga. Biblioteca Universitaria. Normas de Vancouver: guía breve cómo citar y elaborar referencias bibliográficas según las normas de Vancouver Málaga: Biblioteca de la Facultad de Medicina; 2013. [Fecha de Acceso 8 noviembre. 2014].

http://www.sld.cu/galerias/pdf/sitios/histologia/normas-vancouver-buma2013-guia-breve.pdf

2. International Committee of Medical Journal Editors. Recommendations for the Conduct, Reporting, Editing and Publication of Scholarly Work in Medical Journals. [Internet]. [Actualizado Diciembre 2014. Fecha de Acceso diciembre 15. 2014]. Disponible en: http://www.icmje.org

3. Universidad de Murcia. Biblioteca. Gestores bibliográficos. [Internet]. 2012. [Fecha de Acceso 8 diciembre .2014].
Disponible en: http://www.um.es/web/biblioteca/contenido/biblioteca-digital/gestores-bibliograficos

4. Swiss Academic Software. CITAVI: organizar el conocimiento. [Internet].2014 [Fecha de Acceso 8 diciembre .2014]. Disponible en: http://www.citavi.com/es/swiss-academic-software.ht$\mathrm{ml}$.

5. Universidad Nacional Autónoma de Honduras. Capacitan a casi 2000 personas en uso de poderoso buscador bibliográfico CITAVI: [Internet]. Presencia Universitaria. 12 de Marzo del 2014. [Fecha de Acceso 8 diciembre.2014]. Disponible en:

http://www.presencia.unah.edu.hn/academia/articulo/capacitan-a-casi-2000personas-en-uso-de-poderoso-buscador-bibliografico-citavi- 